\title{
Violência na Escola: considerações a partir da formação docente
}

\author{
Jean Mac Cole Tavares Santos* \\ Milene Rejane Pereira ${ }^{* *}$ \\ Érica Renata Clemente Rodrigues***
}

\section{Resumo}

Neste trabalho, apresenta-se alguns resultados de pesquisa realizada com graduandos do curso de licenciatura em Pedagogia da Universidade do Estado do Rio Grande do Norte (UERN) sobre o fenômeno da violência na escola. Tomou-se como referencial teórico para definição e problematizaçáo do conceito de violência os estudos de Andrade, Aquino, Abramovay e Rua, Araújo, Charlot, Bauman e Freire. Discutese, assim, os vários conceitos de violência na escola. Para apreender as concepçóes discentes sobre o assunto, foram entrevistados vinte e oito graduandos do curso de Pedagogia buscando relacionar a compreensáo deles sobre o fenômeno com os estudos sobre o tema. Pensou-se, com eles, que o docente deve partilhar saberes para gerir conflitos de violência na escola, através do diálogo, da ética profissional, da relação social de ensino-aprendizagem.

Palavras-chave: Violência na Escola. Formação de professores. Indisciplina.

*Doutorado em Educação pela Universidade Federal da Paraíba (UFPB). Professor adjunto do Curso de Pedagogia e do Programa de Pós-Graduação, Mestrado em Educação, da Faculdade de Educação, da Universidade do Estado do Rio Grande do Norte (UERN).

** Graduação em Pedagogia pela Universidade do Estado do Rio Grande do Norte (UERN).

*** Graduação em Pedagogia pela Universidade do Estado do Rio Grande do Norte (UERN). Mestranda em Ciências Sociais e Humanas na mesma Universidade. 


\section{Introdução}

A situação da violência na escola tem sido fonte de inúmeras pesquisas que buscam entender o fato como fenômeno social. Trabalhos de fôlego, como Charlot (2002), Andrade (2011), Araújo (2009), Abramovay e Rua (2002), Aquino (1998), vem contribuindo para pensar a definição do objeto estudado e seus principais impactos nos processos de ensino-aprendizagem e na própria condição da escola na sociedade. Apesar da percepção diversa da questão, de suas origens, impactos e consequências, há acordo de que apesar de o problema da violência ultrapassar os limites do espaço escolar, é nele que ela se revela mais fortemente, sendo causadora de exclusão e opressáo, implicando em situaçôes de ineficiência e fracasso escolar. Nesses casos, fica cada vez mais evidente a necessidade de investir na formaçáo docente como instrumento de enfrentamento da atual realidade (ANDRADE, 2011). Dessa forma, em nosso estudo, pretendemos pensar na formação do pedagogo para o entendimento e enfrentamento da situação, partindo da perspectiva de que o educador necessita construir saberes capazes de subsidiar sua práxis, aprendendo a gerir os conflitos existentes ou que envolvem a escola.

A preocupação em discutir esse fenômeno nos espaços escolares, então, vem da necessidade de, no processo de formaçáo dos professores, investigar como os docentes estáo sendo preparados para lidar com a situação que já se manifesta como um dos maiores problemas que afeta a escola. Assim, no presente trabalho, apresentamos e problematizamos algumas concepçóes de graduandos do curso de Pedagogia, adquiridos durante sua formaçáo, em relação à violência na escola.

Para atingirmos nossos objetivos, escolhemos como sujeitos da pesquisa alunos do $8^{\circ}$ período, concluintes do curso de Pedagogia da Universidade do Estado do Rio Grande do Norte (UERN), com exercício na atividade docente, mesmo de forma precarizada, com todos os estágios concluídos e que já realizaram as atividades de Práticas Pedagógicas Programadas (PPP) nas escolas. Dessa forma, eles apresentam olhares sobre a prática pedagógica nas escolas sem, entretanto, a percepçâo cristalizada da realidade oriunda das condiçóes difíceis do ofício docente. Ao todo selecionamos 28 (vinte e oito) discentes para a entrevista através de questionários estruturados. Apesar de não ser uma pesquisa quantitativa, quando a precisão percentual é decisiva, vale salientar que os 28 (vinte e oito) entrevistados correspondem a algo em torno 
de 5\% (cinco por cento) da totalidade de alunos do curso e 50\% (cinquenta por cento) dos alunos concluintes.

O questionário, por sua vez, foi composto de cinco questóes com a intenção de apreender a concepção do entrevistado acerca do conceito de violência e, mais além, perceber a possível diferenciação entre as diversas possibilidades dos usos da violência na escola e na sociedade. Escolhemos perguntas gerais, mesmo sabendo que teríamos mais dificuldades na leitura e análise dos dados, evitando o condicionamento das respostas, buscando nas entrelinhas, nas contradições das falas, nos não ditos, nos silêncios, nas ausências e esquecimentos, aspectos significativos para a construção de nosso discurso (POLLAK, 1989; RICOEUR, 1991). Assim, as questóes foram: 1) Conceitos de violência; 2) Sentidos de violências na escola; 3) Principais tipos de violência existentes no espaço escolar; 4) Principais agressores na relação escola e violência; 5) Principais violências institucionais causadas pela escola.

A partir das respostas analisamos as diversas compreensóes dos conceitos de violência, sua diferenciação na sociedade e na escola, percebendo a ideia de agressores/agredidos contidos nas falas. A partir da análise feita, retomamos as ideias de autores que estudam a escola, a docência e a sala de aula, vislumbrando a possibilidade de superação dos conflitos através da atuação dos professores, com o desenvolvimento de competências e habilidades para mediar conflitos (ANDRADE, 2011), utilizando o método dialógico (FREIRE, 1996) e apontando para a construção da escola pública popular.

Este trabalho está dividido em três partes, além desta introdução. Primeiro definimos violência discutindo com Charlot (2002), Debarbieux (2002), Abramovay e Rua (2002). Depois a discussão sobre violência vista pelos alunos/ docentes. Fechamos as consideraçóes com a ideia de indisciplina como a face mais visível da violência na escola.

\section{Conceituando violência(s)}

Segundo Abramovay e Rua (2002), a percepçáo da violência no meio escolar já passou por várias fases. As análises saíram do estudo sobre a violência do sistema escolar, especialmente por parte dos professores contra os alunos, para a análise da violência praticada entre alunos, contra a propriedade, o chamado vandalismo, de alunos contra professores e de professores contra alunos. Fundamentando-se em Charlot e Émin, as autoras discorrem sobre a dificuldade 
em definir violência escolar, porque esta remete aos fenômenos heterogêneos e, também, porque desestruturam representaçóes sociais fundadores como a ideia de infância e de escola. Dessa forma, "não existe consenso sobre o significado de violência. $\mathrm{O}$ que é caracterizado como violência varia em função do estabelecimento escolar, do status de quem fala [...], da idade e, provavelmente, do sexo" (ABRAMOVAY; RUA, 2002, p. 21).

Buscando retomar a totalidade do debate sobre o assunto, Charlot (2002) amplia o conceito de violência escolar, classificando-a em três níveis. Escapa, assim, da ideia singular de violência e admite o caminho plural das violências, como podemos ver nas classificaçóes abaixo:

a. Violência: golpes, ferimentos, violência sexual, roubos, crimes, vandalismos; b. Incivilidades: humilhaçôes, palavras grosseiras, falta de respeito; c. Violência simbólica ou institucional: compreendida como a falta de sentido de permanecer na escola por tantos anos; o ensino como um desprazer, que obriga o jovem a aprender matérias e conteúdos alheios aos seus interesses; as imposiçôes de uma sociedade que náo sabe acolher os seus jovens no mercado de trabalho; a violência das relaçóes de poder entre professores e alunos. Também o é a negação da identidade e da satisfação profissional aos professores, a obrigação de suportar o absenteísmo e a indiferença dos alunos (CHARLOT, 2002, p. 67).

Podemos observar que, com os três níveis de violências apresentados, há um encontro entre os estudos antigos, àqueles que discutiam a violência no âmbito das instituiçóes, contra os alunos e/ou até contra os próprios professores, e os estudos contemporâneos, com o conceito de violência já ampliado, incorporando as açóes dos sujeitos escolares e da própria sociedade, além das contribuiçóes subjetivistas, psicológicas, que originam termos como violência simbólica e bullying.

Neste texto, ficamos próximos do conceito de violência de Charlot (2002), apresentado acima e também discutido por Abramovay e Rua (2002), pois ele nos possibilita dar alguma denotação ao fenômeno. No entanto, faz-se necessário analisar cada item proposto por Charlot já foi apresentado acima. 
Vendo, no item 'a', violência em si, encontramos aspectos da violência contra pessoas e contra o patrimônio. Apesar de estarem no mesmo patamar, faz-se necessário pontuar a diferença entre eles. A agressão física não pode ser comparada com a destruição de um patrimônio, uma pichaçấo, um mau uso de um dado equipamento, exemplos de violência dentro do que defende Charlot. No mais, o roubo e o furto, comuns nas escolas públicas e privadas, também estariam nesse item e são diferentes entre si, inclusive nos aspectos jurídicos, mas principalmente no tipo de constrangimento, e dano, que pode causar.

Já sobre o item 'b', vale ressaltar, que o conceito de incivilidade é fugidio. Grosso modo, tudo o que é civilizado, cabe dentro das normas sociais. Desse modo, tudo que o item 'a' traz somente como violência é também incivilidade. Por sua vez, e claro dentro dos argumentos até aqui apresentados, são também violência em si.

Sobre o item 'c' tem a questão da violência simbólica como sinônima de violência institucional. Parece verdade que toda violência escolar institucional se apresenta de maneira simbólica, por mais marcas físicas que elas possam vir a apresentar nos sujeitos (como cansaço, tédio, envelhecimento precoce, loucura). Por exemplo: um currículo demasiado agressivo, mal elaborado, causará danos psicológicos e físicos não perceptíveis imediatamente, porém, são danos no corpo (e na alma). Para ponderar, não são, então, menos maléficos, menos violentos aos organismos humanos. Assim, vale salientar, eles são simbólicos não por causa do mal menor que causa ao corpo e, sim, por não se expressar imediatamente, fisicamente no ato.

Com isso, vem outra questão do item 'c': o oposto não é verdadeiro imediatamente. Não seria correto afirmar que toda violência simbólica seja institucional. Outras açôes violentas que atingem o corpo e náo são institucionais como a greve, o motim dos alunos, a rebeldia silenciosa, a reprovação ou a aprovação em massa (sem aprendizagem), o desinteresse do aluno, a ineficácia do professor. São violências que partem do indivíduo ou dos indivíduos que ferem no corpo e na alma e não são contundentes, não revelam num ato violento. São violências simbólicas por se apresentarem através de "símbolos" opressivos e não por serem oriundas de uma institucionalização.

De forma geral, para fechar uma definição necessária a este artigo, a violência pode ser entendida como tudo que ocasiona dor e/ou constrangimento. Do que Charlot (2002) chama, basicamente, de violência, como agressōes físicas ou patrimoniais (que entendemos também serem incivilidades), passando, 
também por Charlot, pelas incivilidades (ofensas verbais, ofensas visuais), até a violência institucional (provas, currículos, horários), mais as violências simbólicas (que ao contrário do que defende Charlot, nem todas são institucionalizas) e mais o que propomos chamar de incivilidades institucionalizadas (baixos salários, autoritarismos, badernas estudantis, greves docentes).

Porém, nessa nova configuraçáo do conceito de violência, agora citando Debarbieux (2002, p. 73), o estudo sobre o assunto deve considerar também:

1. os crimes e delitos tais como furtos, roubos, assaltos, extorsôes, tráfico e consumo de drogas etc., conforme qualificados pelo Código Penal; 2. as incivilidades, sobretudo, conforme definidas pelos atores sociais; 3 . sentimento de insegurança ou, sobretudo, o que aqui denominamos sentimento de violência, resultante dos dois componentes precedentes, mas, também, oriundo de um sentimento mais geral nos diversos meios sociais de referência.

Debarbieux (2002), conforme também discutido por Abramovay e Rua, vem reforçar a definição já ampliada por Charlot, contribuindo com o refinamento do conceito de violência "considerando a populaçáo alvo, os jovens e o lugar da escola como instituição" localizada socialmente. Assim, "a literatura nacional contempla não apenas a violência física, mas acentua a ética, a política e a preocupação em dar visibilidade a violências simbólicas" (DEBARBIEUX, 2002, p. 74).

Entretanto, aliado ao "sentimento de insegurança" de Debarbieux, precisamos considerar as contribuiçóes de BAUMAN (2008) sobre violência e medo. É fácil perceber que junto com o fenômeno violência, ocorrido dentro e fora da escola, está o sentimento de medo, em estado líquido. $\mathrm{O}$ medo líquido é representado, para Bauman (2008), pela carência de certezas, de proteçáo e de segurança em uma sociedade em processo de transformação constante, instável no momento histórico vívido, em que as esperanças de um maior controle e domínio sobre o mundo social e natural depositadas nos tempos modernos se esvaíram. No ambiente líquido pós-moderno as incertezas, perigos e ameaças são uma constante (FRATARI, 2008). Assim, buscamos nas análises de Bauman (2008) explicaçóes para o sentimento de insegurança que sentimos e que, de um modo geral, passamos a sentir em relaçáo aos efeitos que as violências apresentam 
na escola. Afinal, não podemos desconsiderar, vivemos rodeados por notícias de conflitos, ameaças, terrorismos, catástrofes, acidentes, drogas, corrupçóes. $\mathrm{O}$ medo de sermos alvos de tais males tem um lastro real, preocupante. Nas palavras exemplares de Bauman (2008, p. 133):

De maneira altamente dramática, foi demonstrado pelo terrorismo o grau de insegurança que sentimos vivendo em um planeta negativamente globalizado e o modo como a "defasagem moral" - responsável pelo aprofundamento das contradiçôes entre o caráter remoto dos efeitos provocados pelas nossas açốes e o curto espectro das preocupaçóes que as modelam - torna dificilmente concebível qualquer fuga do estado de incerteza endêmica, da insegurança e do medo que esta alimenta.

Não é fácil fugir da contaminação da ideia de que somos os próximos alvos da situaçáo calamitosa por qual passamos. O medo, o pavor da insegurança, como uma presa prestes a ser atacada por seu predador, só aumenta. Certamente, o medo, tendência na (pós) modernidade líquida, vem ocupando os espaços educativos, de maneira desenfreada, fato percebido na ânsia, no estresse dos professores, com dificuldades de diagnosticar com mais cuidado os perigos e contribuindo para a exacerbação da situação do estado de medo.

Com isso, entendemos ser necessário aproveitar as contribuiçôes de Debarbieux e Bauman na definição do conceito de violência, atentando que o referido conceito precisa ter o cuidado de separar a violência do medo da violência. Não estamos dizendo que tal atitude é de fácil consecução; estamos admitindo que a violência, em sua difícil definição, terá que enfrentar também esse desafio. Pois, sob a ótica de Bauman (2008), cada elemento de violência citados para compor a definição ganha dimensão ampliada. Sobre cada elemento paira uma grande lupa, lente de aumento e de distorção do evento (e da possibilidade dele) produzindo e reproduzindo a escola do medo, fruto da sociedade do medo.

Como exemplo da grande lupa, podemos citar o aumento de casos de escolas fechadas, no Brasil inteiro, devido a ataques ou ameaças por bombas. Em um dos casos, o Jornal $O$ povo, de Fortaleza, noticiou a situação de uma escola que passou uma semana fechada após um aluno atacar o banheiro da escola com uma 'bomba caseira de pequeno porte'. Na verdade, ao ler a notícia, percebemos 
que se tratava de um artefato junino, chamada no nordeste de "bomba rasgalata”. Apesar do barulho que causa, não parece motivo para criminalizar o ato ou de transformá-lo em ameaça terrorista a ponto de a escola ser fechada até os culpados serem detectados e punidos. Noutros tempos, trataríamos somente como vandalismo comum e buscaríamos medidas para atenuar o malfeito do menino indisciplinado. Hoje é aberto inquérito policial, o malfeito se transforma em crime e a escola percebe-se refém do terrorismo como no Afeganistão, no Iraque, nos EUA. Estamos todos sob a mesma ameaça? Ou a lupa distorce, aumenta e aproxima realidades díspares? Fica claro que olhamos a realidade com a lupa do medo, transformando a escola e os sujeitos nela presentes em ameaça constante.

Vendo dessa perspectiva, o medo não gera medrosos, gera valentôes. Cada indivíduo ou grupo pretende desenvolver sua forma de atacar o problema. $\mathrm{Na}$ raiz de todos os elementos, o medo se transforma em ação contra a violência que gera mais violência. As ações pedagógicas, em tal contexto, vão perdendo assento para açóes policiais e judiciais. O medo tomou lugar-tenente na escola.

Dessa forma, merece atenção também outra contribuição trazida por Abramovay e Rua (2002). Apoiando-se, principalmente, em Sposito elas apresentam a relação entre violência e a quebra de diálogo. $\mathrm{O}$ diálogo, como apresenta também Freire (2002), quando é substituído pelo uso da força por uma das partes, ocasiona todo tipo de violência, pois rompe, unilateralmente, a possibilidade de busca pelos encontros possíveis. Os encontros possíveis, diferentemente da ideia habermasiana de consensos possíveis, valoriza as falas, as açôes, as diferenças entre os sujeitos, mas do que a busca pela superação do conflito em si. Aqui, a existência do conflito não é sinônimo automático de violência. Em outras palavras, superar os conflitos não é, necessariamente, a maior tarefa na busca pela superação da violência. $\mathrm{O}$ aprender a conviver em situação de conflitos, não levando o estado conflituoso a um estado de violência, é, sim, a atividade da busca pela paz.

\section{A violência vista pelos alunos/docentes}

Nossos entrevistados são alunos concluintes do curso de Pedagogia, com todas as disciplinas de práticas cursadas, como as práticas pedagógicas e os estágios supervisionados, além de exercerem a função docente como professores de apoio, substitutos ou estagiários nas escolas dos municípios e do estado. Enquanto alunos continuam estudando e refletindo teorias e práticas em busca do fazer 
docente de qualidade. Como docentes e aprendizes sentem as diversidades e as adversidades da sala de aula, os medos, as ausências, a falta de estrutura, o baixo salário, a falta de tempo, entre tantas outras dificuldades da profissão. $\mathrm{O}$ encontro dessas duas circunstâncias é primoroso para discutirmos os elementos da violência e das condições para a superação das situações de violências nas escolas.

Foi com a compreensão dessa especificidade, com relação aos depoentes, que aplicamos os questionários estruturados aos vinte e oito entrevistados. Após a análise dos questionários, sistematizamos os dados, sinteticamente, por questão respondida. Assim, buscamos a síntese das falas construindo "a fala tipo ideal" de cada uma das perguntas. Desse modo, apresentamos a "fala tipo ideal" fazendo, quando necessário, comentários e discussóes sobre indicadores que não foram majoritários nas respostas, mas que podiam indicar bons elementos para entender as questōes aqui levantadas. A seguir nomearemos cada uma das perguntas realizadas com a síntese/resposta por nós construída.

A primeira questão, conceitos de violências, pode ser assim sintetizada:

Säo as açöes ou palavras que causam danos físicos e
psicológicos à pessoa agredida. Não se refere somente a força
fisica, mas também às palavras com sentidos pejorativos
ou de baixo caláo. Representado como o ato de uma pessoa
agredir a outra pessoa, tal agressáo pode ser verbal, física ou
psicológica. Geralmente causada pela falta de tolerância a
um comportamento ou atitude de alguém; quem sofre nunca
esquece, pois a violência deixa marcas no corpo e na alma.

O conceito para os entrevistados gira em torno da agressão de um sujeito (o agressor) contra outro sujeito (o agredido). Várias outras formas de violência ficaram ausentes da definição construída. No entanto, a grande maioria apresentou a ideia de que a violência deixa marcas físicas ou psicológicas. Outra questão é que alguns entrevistados (3) deixaram a possibilidade de num dado momento agressor e agredido trocarem de papéis. Isto é, não há predominância universal de quem é o agressor e de quem é o agredido.

A segunda questão, sentidos de violências na escola, pode ser assim consolidada:

A violência na escola não foge ao significado geral de violência. São todas as práticas verbais ou açóes que são proferidas contra colegas, professores, funcionários etc. A 
violência escolar é mais conhecida hoje como bullying, que em geral são mais praticadas pelos alunos através de palavras pejorativas, palavröes, difamaçôes, intrigas e agressóes físicas. Alguns funcionários e professores também podem ser vitimas ou agressores. É também vista como um fenômeno que tomou conta das escolas. Quase nada pode ser feito, pois a violência já está presente em todas as escolas atingindo todos indistintamente, principalmente o aluno. É necessário retomar novas formas de solidariedade e exigir segurança por parte dos governos. É inadmissivel o quadro geral de desrespeito e agressóes presenciados todos os dias. O lugar que já foi tido como o mais seguro, que dava tranquilidade para os pais por saberem que os filhos estavam nas escolas, está mais perigoso que a rua.

Encontramos nas entrevistas a repetição do termo bullying como sinônimo de violência na escola, podendo ser realizado (ou sofrido) tanto pelos alunos e seus pares quanto por funcionários e professores. Interessante perceber como a palavra bullying ganhou terreno no vocabulário da violência nas escolas, nos últimos cinco anos, mesmo sem muita precisão conceitual e com a dificuldade de enquadrá-la dentro dos problemas relacionados à violência que rodeiam hoje as escolas.

$\mathrm{Na}$ relação com a questão anterior, podemos visualizar que a diferenciação entre os conceitos de violência e o de violência na escola se dá somente pelos sujeitos escolares diretamente envolvidos. Na primeira questáo, é mostrado ato de violência como cometido por qualquer indivíduo; já na segunda questão os sujeitos, agentes provocadores (ou que sofrem) dos atos de violência, são precisamente alunos, funcionários e professores. Há ainda o esquecimento que a escola também pode ser o agente impulsionador de violência através de suas regras institucionais; ou, mesmo, que a sociedade pode transportar a violência para dentro da escola como, por exemplo, drogas, gangues e assaltos.

$\mathrm{Na}$ terceira questáo, quais os principais tipos de violência presenciados no espaço escolar, podem ser sistematizados da seguinte forma:

A violência verbal e física entre os alunos são as mais comuns na escola motivados por desrespeito e ausência de diálogo. Acontece muito desrespeito, muita confusão, muito conflito entre alunos e entre alunos e professores. A falta de segurança e autoridade aumenta ainda as condiçóes para as brigas e as 
'brincadeiras de mau gosto' entre os discentes. Há também o abuso de poder por parte de professores e funcionários da escola contra os alunos. Os professores ainda cometem abuso de violência verbal contra os alunos com gritos e ameaças. Em menor caso acontece também a violência física de alunos contra professores.

Salientamos que 14 (catorze) graduandos indicaram que já presenciaram agressão física entre alunos na escola. Sobre agressão verbal, 22 (vinte e dois) indicaram ser comum esse tipo de ação entre alunos. Com relaçáo ao autoritarismo dos professores, seis entrevistados já testemunharam açôes agressivas dos professores contra os alunos. Não conseguimos detectar nas entrevistas nenhum caso de uso ou tráfico de drogas, de violência sexual, de roubo ou mesmo de depredação do patrimônio da escola, como atos violentos encontrados nas escolas apesar do discurso geral do "estado incontrolável de violência na escola”.

A quarta questão, sobre os principais agressores na relação escola e violência, foram detectadas, majoritariamente, as seguintes respostas:

Os alunos são os principais agressores; são eles que cometem as açóes contra outros alunos e contra os professores dificultando o clima de aprendizagem em sala de aula. A bagunça atrapalha o aprendizado, dificultando que todos aprendam o conteúdo. Depois são os professores que cometem muitas agressóes, principalmente, exigindo respeito por parte dos alunos que já não reconhecem sua autoridade em sala de aula. A comunidade também tem sua parcela de culpa, mas em nivel menor já que tem pouco acesso à escola. A família não agride muito. A direção da escola tem seu papel na violência, mas não tanto quanto alunos e professores.

Temos assim, mais uma vez, os alunos e professores como principais agentes dos conflitos de violência e, agora, com a possibilidade da violência docente ser em resposta ao estado de violência precipitado pelos alunos. Isso ocorre devido a imagem da necessidade de determinado "clima de atenção para as atividades de sala de aula", entendida como a "ação do professor que ministra as aulas" e a "ação dos alunos que assistem ao que é repassado", como define uma entrevistada. Dessa maneira, por ser na sala de aula onde professores 
e alunos passam a maior parte do tempo das atividades escolares, sendo mais visíveis as açóes ali executadas, fica mais localizada naquele espaço tanto as questôes detectadas pelos entrevistados como também onde os conflitos mais são percebidos. Aí pode estar o porquê dos conflitos serem maiores entre professores e alunos. Os outros membros da escola ficam, então, menos visíveis diante dos conflitos. Outro dado importante é a percepção que o professor sente que não tem mais autoridade na sala de aula; os alunos também percebem que a autoridade do professor não existe mais, gerando clima de "desleixo" com o aprendizado.

A quinta questão, referente às principais violências institucionais causadas pela escola, resultou na seguinte síntese:

O que mais acontece é abuso de autoridade por parte de professores e funcionários. Esse abuso se revela através da exigência de muitos conteúdos e da manutenção de determinada ordem que nem sempre é compartilhada por todos que fazem a escola. Acontece que em nome das normas estabelecidas pela escola é possivel perceber muitas humilhaçōes. Reprovação e evasão são também duas violências que a escola comete contra os alunos e a sociedade. Outro aspecto violento observado diz respeito às provas e notas. Por fim, a exigências de regras de condutas, de horários, de fardas, de posturas são também apresentados como uso demasiado de violência pela instituiçáa escolar. A escola exige demais em coisas sem importância (como fardamento, boné, piercing) e deixa solta em outras. Pune por coisas simples e deixa sem punição açôes mais graves, violentas (como o desrespeito contra os docentes e outros alunos).

Como vimos, mesmo numa pergunta direcionada para a questáo da violência institucional, são professores e funcionários que aparecem como os maiores causadores de violência.

De modo geral, aqui, o aluno toma o lugar de vítima. Considerando que o aluno também é vítima quando outros alunos são os agressores, vemos que há o entendimento geral dos entrevistados que a violência recai mesmo é sobre os alunos. Interessante notar que pela primeira vez, e somente porque a pergunta era direcionada para a questáo, a institucionalizaçáo da escola (farda, provas, notas, regras) é apontada como elementos de violência. Assim 
mesmo, os entrevistados mostram que o foco da ação da escola na violência institucionalizada deveria estar voltado para a disciplina, e não para a contenção dos horários, roupas e bons modos dos alunos.

\section{A indisciplina como a face mais visível da violência na escola}

De forma geral, podemos detectar que a maioria dos discursos relaciona violência na escola com a indisciplina, o que, com Charlot, discutimos como incivilidades. A indisciplina, como face mais visível da violência na escola, revelada através da quebra da harmonia necessária para as relaçóes pedagógicas acontecerem em sala de aula. Expressóes tipo bagunça, inquietação, agitação, conversas paralelas, entre outras, revelam a concepção que a sala de aula deve ser um ambiente calmo, silencioso, ordenado, disciplinado. Para Aquino (1996, p. 85-86),

Um comportamento inadequado, um sinal de rebeldia intransigência, desacato, traduzida na falta de educação ou de respeito pelas autoridades, na bagunça ou agitação motora. Como uma espécie de incapacidade do aluno (ou de um grupo) em se ajustar às normas e padrôes de comportamento esperados. [...] Nesta perspectiva, qualquer manifestação de inquietação, questionamento, discordância, conversa ou desatenção por parte dos alunos é entendida como indisciplina, já que se busca obter a tranquilidade, o silêncio, a docilidade, a passividade das crianças de tal forma que não haja nada nelas nem fora delas que as possa distrair dos exercícios passados pelo professor, nem fazer sombra à sua palavra.

O professor, e somente ele, centro de todas as atençóes, autoridade de saber, de ordem, de determinaçáo, de onde emanam todas as decisóes, respostas e perspectivas de produção do conhecimento. A indisciplina, violenta tal pressuposto, recoloca os sujeitos em patamares de disputa, desorganiza, reorganiza a lógica docêntrica, autoritária, instituída na sala. Impóe que algo dado, absoluto, historicamente constituído como certo e inevitável, necessite ser reafirmado, imposto. No processo de reafirmação da supremacia docente surge o vácuo, espaço de questionamento, de conflito de interesses, de necessária indagaçáo de o porquê que as coisas são assim. 
A fala maioral de nossos entrevistados relacionando violência com indisciplina inspira mais uma constatação: o professor quer/precisa se afirmar, e essa afirmação acontece antes na sala de aula, através da máxima do "domínio de sala", sinônimo, muitas vezes, de manutençâo da ordem e de autoritarismo; ser professor é dominar uma sala de aula, manter a ordem, organizar a turma, colocar cada um em seu devido lugar e, somente depois, propiciar aprendizagem ao discente.

A manutençáo da ordem, a disciplina dada pelo mestre/maestro (aquele que rege a sala), é que determina a aprendizagem, não o contrário. Não é a aprendizagem, a construçáo e encontros de saberes gerando ambiente de amizade, de harmonia, de alegria e de paz. É justamente um ambiente seco, fechado, impalatável, ranzinza, que forjará a leitura, a escrita e as primeiras somas e subtraçóes matemáticas. A escola não como segunda casa, mas como o castigo nosso de cada dia.

Vale ressaltar, no entanto: a lógica do "domínio de sala", a lógica docêntrica, não é invenção docente. É elaboração histórica da escola (situada socialmente) que atende ao modelo representativo de sociedade. Todos os que fazem a escola, alunos, professores e funcionários, mais família e comunidade, mais autoridades e muitos estudiosos, comungam da ideia da disciplina, executada pelo professor, como pré-requisito para a aprendizagem (AQUINO, 1998).

$\mathrm{Na}$ contramão da manutenção da ordem, só poderiam ser os alunos os maiores agressores. Apesar de fazerem parte do consenso, são eles quem sentirão, no corpo, a ação disciplinar. Assim, entendemos que um dos motivos deles aparecerem nos discursos como os maiores agressores se deve a concepçáo de que são eles os únicos que podem, de dentro do problema, desafiar a lógica imposta do bom comportamento numa relação horizontal. Os corpos que necessitam de disciplinamento são os corpos discentes, o corpo discente. E é exatamente este o corpo da indisciplina, reconhecidamente indisciplinado, patrocinador da quebra da lógica disciplinar.

$\mathrm{Na}$ mesma medida, são os alunos também as maiores vítimas. Tanto são vítimas em maior escala por estarem em quantidade superior aos demais membros da escola, como também por sofrerem as consequências, as açóes dos atos disciplinares, e estarem, do ponto de vista hierárquico, na mesma condição dos maiores agressores, os próprios alunos.

Um dado importante que conseguimos detectar foi a persistência que os participantes fizeram nas primeiras questôes em se tratando dos atos de violência 
e dos principais agressores como situaçóes provocadas, somente, entre alunosalunos, alunos-professores e nunca da instituição contra seus sujeitos, como por exemplo, quando a escola impóe regras e puniçóes.

Na medida em que as puniçóes sáo, na maioria das vezes, estipuladas de forma arbitrária, a escola pode ser um lócus privilegiado do exercício da violência simbólica. A violência, nesse caso, seria exercida pelo uso de símbolos de poder que não necessitam do recurso da força física, nem de armas, nem do grito, mas que silenciam protestos. (ABRAMOVAY; RUA, 2002, p. 34-35).

Essa última questão possui uma ferramenta importante para percebermos como a escola carrega uma imagem de "ordem", de querer tudo em ordem, uma verdadeira disciplina, por esse motivo fica pouco visível seu papel de reflexiva nas questóes de se sensibilizar com o ofício de professor, como se a relação professor-aluno fosse uma relação que não ultrapassasse a sala de aula, e quando ultrapassa, a decisão é mesmo de punição.

$\mathrm{O}$ abuso de autoridade, ora pouco citado como o menos provocador de conflitos de violência, ganha nesta questão, um respaldo; como o mais indicado o autoritarismo, impulsionado pela escola, citado pelos graduandos, também atende aos indicadores dos próprios alunos, como comprova a pesquisa de Abramovay e Rua (2002, p. 35):

Existem reclamaçôes de alunos em relação aos diretores. Entre as queixas mais frequentes que apresentam alunos em relação a diretores, destacam-se: não visitarem as salas de aula; não se reunirem com representantes de turma; estarem ausentes da rotina escolar; agirem de forma autoritária; darem um tratamento diferenciado aos alunos, tratando-os bem quando acompanhados dos pais.

Identificamos a aproximação de ideias entre futuros profissionais da educaçáo e de alunos da rede básica de ensino, expostos cotidianamente nas situaçóes conflituosas de violência, e enfatizamos a urgência de medidas socioeducativas como preventivas. Também não descartamos a influência que as mudanças externas proporcionam à escola. 
A humilhação, causada pelas autoridades da escola à segunda indicada, revela a sujeição em que os alunos estão imersos, uma vez que ganha um papel inaceitável para Paulo Freire, o de oprimido. Segundo as ideias freirianas, é por meio do diálogo que encontramos a premissa inicial de qualquer relação existente entre os seres, onde podemos avançar numa relação aberta sem privilégio de professor ao aluno. Assim, é necessário que as instituições de ensino invistam em conscientizar seus profissionais, pais e alunos sobre a relevância desse tema e desenvolvam estratégias preventivas, em parcerias com os diversos segmentos sociais, visando educar para a paz. "Onde quer que estejam estes, oprimidos, o ato de amor está em comprometer-se com sua causa. A causa de sua libertaçáo. Mas, este compromisso, porque é amoroso, é dialógico" (FREIRE, 2005, p. 92).

\section{REFERÊNCIAS}

ABRAMOVAY, Miriam; RUA, Maria das Graças. Escola e violência. Brasília, DF: UNESCO, 2002.

ANDRADE, Fernando Cezar Bezerra. Competência Docente para gestão de conflitos: inspiraçóes freirianas In: SANTOS, Jean Mac Cole Tavares (Org.). Paulo Freire: teorias e práticas e educação popular- escola pública, inclusão, humanização. Fortaleza: Edições UFC, 2011. p. 90-105.

AQUINO, Júlio Groppa (Org.). Indisciplina na escola: alternativas teóricas e práticas. São Paulo: Summus, 1996.

AQUINO, Júlio. A violência escolar e a crise da autoridade docente. Sáo Paulo: Summus, 1998.

ARAÚJO, José Prata. Guia dos direitos sociais: a igualdade social e as diferenças entre a esquerda e os neoliberais. São Paulo: Fundação Perseu Abramo, 2009. p. 143-150.

BAUMAN, Zygmunt. Medo líquido. Rio de Janeiro: Jorge Zahar, 2008.

CHARLOT, Bernard. A violência na escola: como os sociólogos franceses abordam essa questão. Revista Sociologias, Porto Alegre, RS, n. 8, jul./dez. 2002.

DEBARBIEUX, Eric. Violência na escola: dez abordagens europeias. Brasília: UNESCO, 2002. 
FRATTARI, Najla Franco. Insegurança e medo no mundo contemporâneo: uma leitura de Zygmunt Bauman. Sociedade e Cultura, Goiânia, v. 11, n. 2, p. 377-389, jul/dez. 2008.

FREIRE, Paulo. Pedagogia da Autonomia: saberes necessários à prática educativa. 37 ed. São Paulo: Paz e Terra, 1996.

FREIRE, Paulo. Pedagogia da Autonomia: saberes necessários à prática educativa. São Paulo: Paz e Terra, 2002.

FREIRE, Paulo. Pedagogia do oprimido. Rio de Janeiro: Paz e Terra, 2005.

POLLAK, Michel. Memória, esquecimento, silêncio. Estudos Históricos, Rio de Janeiro, v. 2, n. 3, 1989.

RICOEUR, Paul. O si mesmo como um outro. Campinas, SP: Papirus, 1991. 


\section{Violencia escolar: School violence: consideraciones en la considerations based on the formación del profesorado teaching practice}

\section{Resumen}

Se presentan los resultados de las investigaciones realizadas con estudiantes de Pedagogía (UERN) sobre el fenómeno de la violencia escolar. Tomamos como un concepto teórico para cuestionar los estudios de Andrade, Aquino, Abramovay y Rua , Araújo, Charlot, Bauman y Freire. Se discuten los distintos conceptos de violencia en la escuela. Para captar a los estudiantes conceptos sobre el tema, se entrevistó con veinte y ocho graduados que buscan relacionar su comprensión del fenómeno con los estudios sobre el tema. Creemos que, con ellos, que los profesores deben compartir sus conocimientos para manejar los conflictos de violencia escolar a través del diálogo, la relación social de la enseñanza y el aprendizaje.

Palabras claves: La falta de disciplina en la escuela. La violencia. La formación docente. Pedagogía.

Jean Mac Cole Tavares Santos

E-mail: maccolle@hotmail.com

Milene Rejane Pereira

E-mail: milene_rejane@hotmail.com

Érica Renata Clemente Rodrigues

E-mail: erica_qib@hotmail.com

\section{Abstract}

We present results of research conducted with undergraduate students of Pedagogy UERN about the phenomenon of school violence. We take as a theoretical concept for questioning the studies of Andrade, Aquino, Abramovay and Rua, Araújo, Charlot, Bauman and Freire. We discuss the various concepts of violence at school. To grasp the concepts students on the subject, interviewed twentyeight graduates seeking to relate their understanding of the phenomenon with the studies on the subject. We think, with them, that teachers should share their knowledge to manage conflicts of school violence through dialogue, the social relationship of teaching and learning.

Keywords: Llack of discipline in school. Violence. Pedagogy. Teacher training.

Recebido em: $2 / 8 / 2012$

Versão final recebida em: 30/1/2013

Aprovado em: 1/3/2013

PERSPECTIVA, Florianópolis, v. 31, n. 2, 573-590, maio/ago. 2013

http://www.perspectiva.ufsc.br 